\title{
Practical Application of Low-Cost Sensors for Static Tests
}

\author{
Seyedmilad Komarizadehas ${ }^{1}$, Behnam Mobaraki ${ }^{2}$, Jose A. Lozano-Galant ${ }^{2}$, and Jose \\ Turmo ${ }^{1}$
}

\author{
${ }^{1}$ Department of Civil and Environment Engineering, Universitat Politècnica de Catalunya, \\ BarcelonaTech. C/ Jordi Girona 1-3, 08034, Barcelona, Spain. Seyedmilad.komarizadehasl@upc.edu, \\ jose.turmo@upc.edu \\ ${ }^{2}$ Department of Civil Engineering, Univesidad de Castilla-La Mancha. Av. Camilo Jose Cela s/n, \\ Ciudad Real, 13071, Spain.behnam.mobaraki@uclm.es, Joseantonio.lozano@uclm.es
}

\begin{abstract}
Structural Health Monitoring (SHM) is essential to assess the accuracy of durability predictions of structures. Using low-cost sensors on structural evaluation has gained significant attention compare to high-cost sensors. Although these may not be as accurate and sensitive as the expensive electronic devices, with efficient code and right use, there is a possibility of getting useful information from them. These sensors can vary based on their functionality and the measurements they provide. For example, one is highly sensitive to the light of its environment while the other kind would give different results in different temperatures. In this paper, three different displacement measuring sensors have been studied. An ultrasonic sensor (HC-SR04) and two different types of laser sensors (VL53LOX and VL53L1X) are investigated in the paper. An Arduino Mega has captured their measured data, and a raspberry pi has made the acquisition. Not only issues regarding coding and placing of these sensors have been presented ultimately, but precise solutions for the aforementioned problems as well as an efficient way of assembling all the sensors are also presented in this paper. The data generated from these electronic devices can be used for Structural Health Monitoring applications.
\end{abstract}

Keywords: Low-Cost Sensors, Distance Measurement, Internet Of Things (IoT), Accuracy and Sensibility, Structural Health Monitoring.

\section{Introduction}

Recently, the need for using sensors in structures for monitoring and inspection of their health state is growing. With this, the need for more economical means of doing SHM is getting very great attention. In this paper, a few models of static sensors have been presented. Moreover, the characteristics of each of them have been explained. Each type could be used in specific situations, and each one has advantages as well as disadvantages in different ambient (Komarizadehasl et al., 2020a; Komarizadehasl et al., 2020b). For being able to work with these sensors, first briefly, Arduino Uno (which is the central programable logic controller (PLC) in this project) would be introduced. Secondly, three different types of ranging sensors would be introduced along with their specifications. Each type of sensor may use a different way to send its data. Thirdly, different ways of communicating with this PLC will be presented. Finally, the results of these sensors against different situations, objects, and colors would be illustrated (Mobaraki et al., 2020; Mobaraki and Vaghefi, 2016). 


\section{State of the Art}

In this section, the sensors and a microcontroller that has been used in the project will be reviewed along with their technical descriptions.

\subsection{Arduino Uno}

Arduino (Figure 1) is an open-source electronics platform based on easy-to-use hardware and software. Arduino Uno is a microcontroller board based on the ATmega328P. It has 14 digital input/output pins, six analog inputs to measure and convert the voltage to a digital value. It facilitates numerous interfaces to communicate with other microcontrollers and computers such as Inter-Integrated Circuit (I2C), Serial Peripheral Interface (SPI), and Universal asynchronous receiver/transmitter (UARTA). The board can work on an external power supply via a USB port or a power jack. An integrated development environment (IDE) is available for writing, compiling, and developing the code. This IDE supports a dialect of $\mathrm{C} / \mathrm{C}++$ using specific regulation of code organizing (Pasha, 2016).
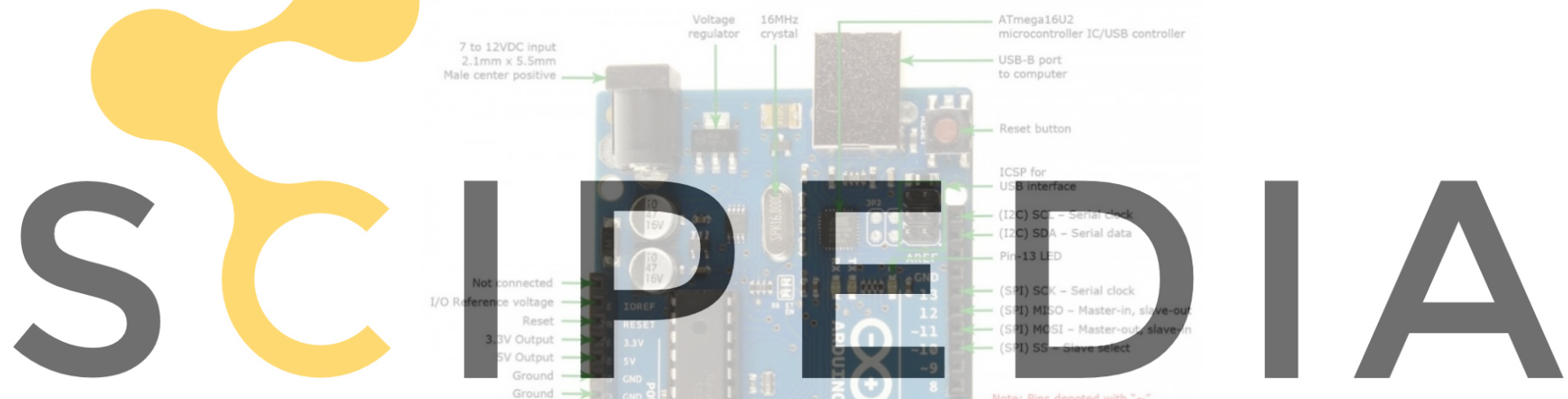

Register for free at https//www:scipedia.com to download the version without the watermark

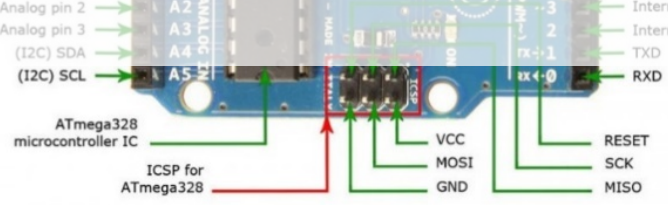

Figure 1. Schematic of the Arduino Uno.

\subsection{Ultrasonic Sensors}

Ultrasonic ranging module HC - SR04 (Figure 2) provides $2 \mathrm{~cm}-400 \mathrm{~cm}$ non-contact measurement function, the ranging accuracy can reach to $3 \mathrm{~mm}$. The modules have transmitters, receivers, and processing circuits. The basic concept of work is: firstly, using the I $\backslash \mathrm{O}$ trigger for at least $10 \mathrm{uS}$ (microsecond) high-level signal. Secondly, The Module automatically sends a frequency of $40 \mathrm{kHz}$ and detects whether there is a pulse signal back. Finally, the range can be calculated through the time interval between sending trigger signals and receiving an echo signal. Test distance $=($ time $\times$ velocity of sound $(340 \mathrm{M} / \mathrm{S}))($ Kamal and Hemel, 2019). The technical specification of the use sensor is in Table 1. 


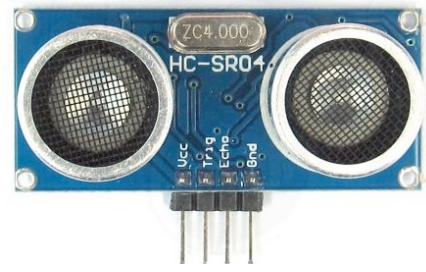

Figure 2. Schematic of an Ultrasonic ranging module HC-SR04.

Table 1. Technical specification of the ultrasonic sensor.

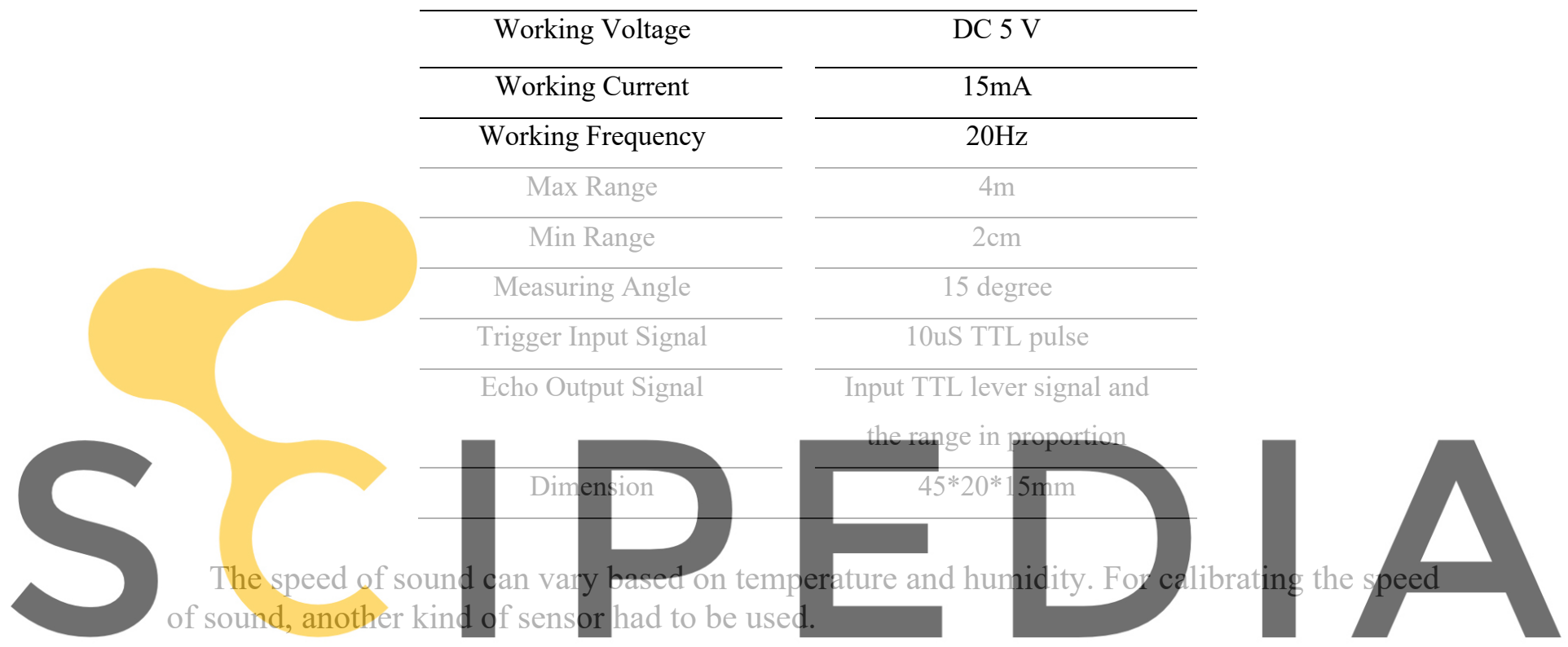

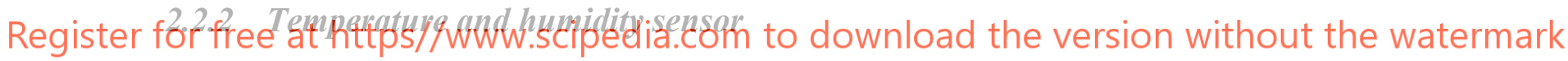

As it has been written in section 2.2, for measuring the distance using that sensor, the speed of sound is needed. The sound travels at different speeds in different temperatures and humidity. DHT22 (Figure 3a) has already been calibrated during the production process and provides accurate information (Liu, 2013). The technical specification of the use sensor is in Table 2. Wire connecting illustration is as follows:

a)

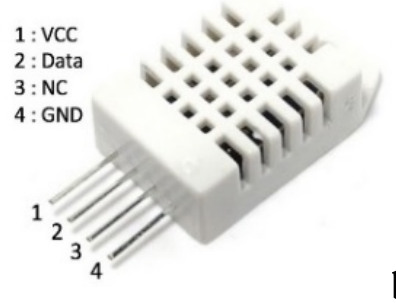

b)

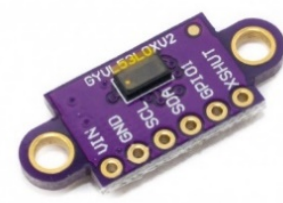

c)

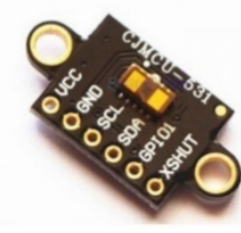

Figure 3. a)Schematic of a DHT22, digital temperature, and humidity sensor, b) Schematic of a VL53L0X, c) Schematic of a VL53L1X. 
Table 2. Technical specification of DHT22.

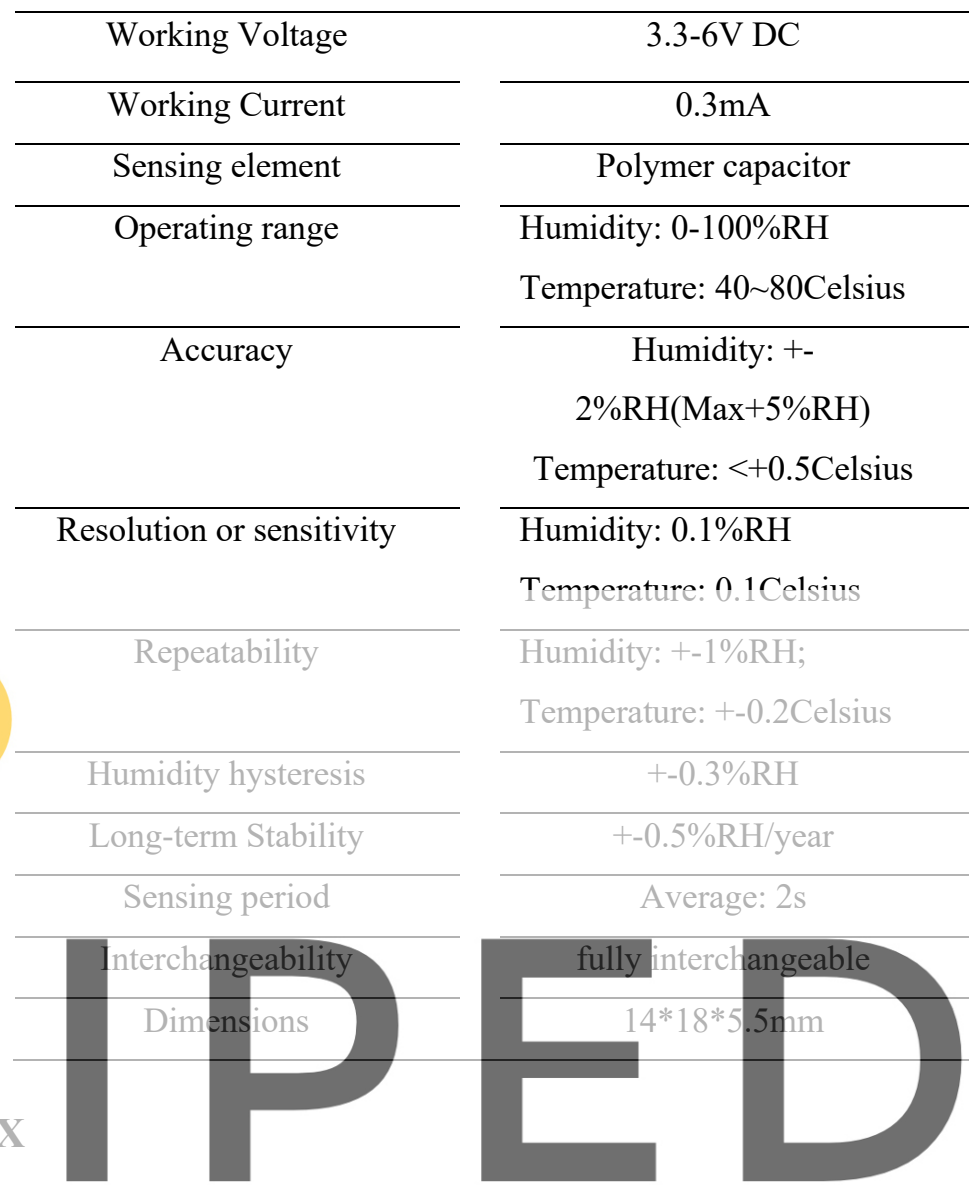

The VL53L0X (Figure 3b) is a new generation Time-of-Flight (ToF) laser-ranging module

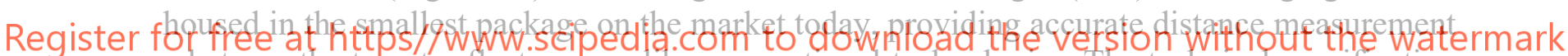
whatever the target reflectance, unlike conventional technologies. The technical specification of the use sensor is in Table 3.

Table 3. Technical specification of VL530L0X.

\begin{tabular}{|c|c|}
\hline Working Voltage & $2.6-5.5 \mathrm{~V} \mathrm{DC}$ \\
\hline Working Current & $10 \mathrm{~mA}$ up to $40 \mathrm{~mA}$ \\
\hline Working Frequency & $50 \mathrm{~Hz}$ \\
\hline Output format $\left(\mathrm{I}^{2} \mathrm{C}\right)$ & $\begin{array}{l}\text { 16-bit distance reading (in } \\
\text { millimeters) }\end{array}$ \\
\hline Distance measuring range & $\begin{array}{c}\text { Up to } 2 \mathrm{~m} \text { with a minimum } \\
\text { range of } 3 \mathrm{~cm}\end{array}$ \\
\hline $\begin{array}{l}\text { Weight without header } \\
\text { pins }\end{array}$ & $0.5 \mathrm{~g}$ \\
\hline Dimension & $13 * 18 * 2 \mathrm{~mm}$ \\
\hline
\end{tabular}


It can measure absolute distances up to $2 \mathrm{~m}$, setting a new benchmark in ranging performance levels, opening the door to various new applications. The VL53L0X integrates a leading-edge SPAD array (Single Photon Avalanche Diodes) and embeds ST's second generation FlightSenseTM patented technology. The VL53L0X's $940 \mathrm{~nm}$ VCSEL emitter (Vertical-Cavity Surface-Emitting Laser), is invisible to the human eye, coupled with internal physical infrared filters, it enables longer ranging distances, higher immunity to ambient light, and better robustness to cover glass optical crosstalk (Adafruit, 2016).

\subsection{The VL53L1X}

The VL53L1X (Figure 3c) is a state-of-the-art, Time-of-Flight (ToF), laser-ranging sensor, enhancing the ST FlightSense ${ }^{\mathrm{TM}}$ product family. It is the fastest miniature ToF sensor on the market with accurate ranging up to $4 \mathrm{~m}$ and fast ranging frequency up to $50 \mathrm{~Hz}$ Housed in a miniature and reflowable package, it integrates a SPAD receiving array, a $940 \mathrm{~nm}$ invisible Class 1 laser emitter, physical infrared filters, and optics to achieve the best ranging performance in various ambient lighting conditions with a range of cover window options. Unlike conventional IR sensors, the VL53L1X uses ST's latest generation ToF technology, which allows absolute distance measurement, whatever the target color and reflectance. It is also possible to program the size of the ROI on the receiving array, allowing the sensor FoV to be reduced. The technical specification of the use sensor is in Table 4.

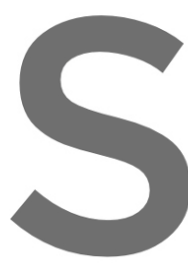

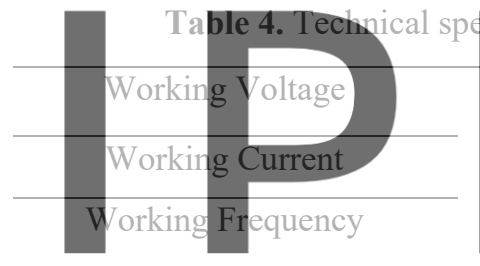

1-Short: up to $\sim 130 \mathrm{~cm}$

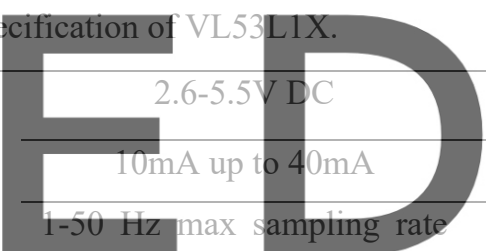

(most immune to interference
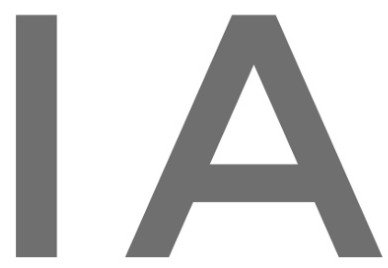

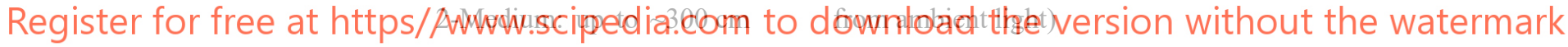
in the dark

3-Long: up to $400 \mathrm{~cm}$ in 2- 30 Hz max sampling rate

the dark

\begin{tabular}{c}
\hline Output format $\left(\mathrm{I}^{2} \mathrm{C}\right)$ \\
\hline Distance measuring range \\
\hline Weight without header \\
pins \\
\hline
\end{tabular}

3- $30 \mathrm{~Hz}$ max sampling rate

16-bit distance reading (in

millimeters)

Up to $2 \mathrm{~m}$ with a minimum range of $4 \mathrm{~cm}$

Dimension

$13 * 18 * 2 \mathrm{~mm}$ 


\subsection{Price}

In Table 5, information regarding prices of the introduced sensors has been given, VAT included.

Table 5. Price of used electronic gadgets.

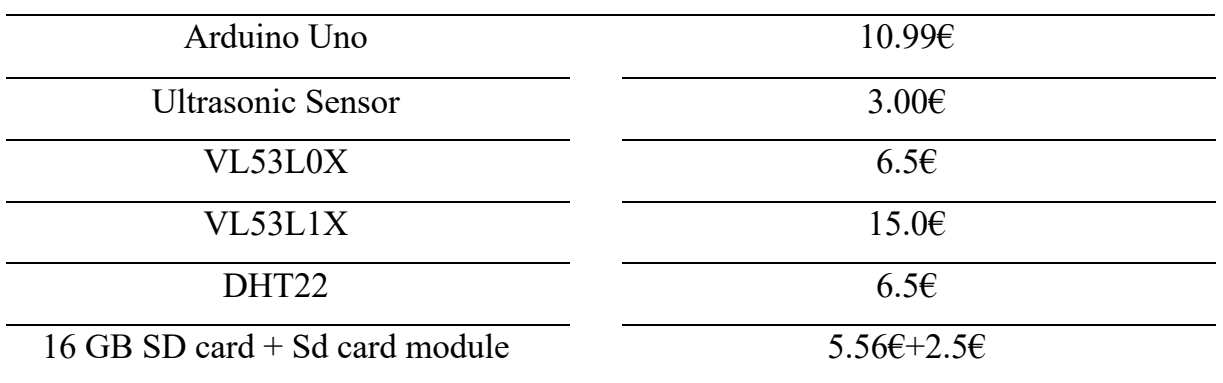

\section{Communication Ways}

While many sensors use digital and analog ports for uploading the measured data to the microcontroller, some sensors use the inter-integrated circuit (I2C) protocol. This is a protocol that allows multiple "slave" digital integrated circuits (Sensors) to communicate with one or more "master" chips (Arduino). Like the Serial Peripheral Interface (SPI), which is only DHT22 have been connected to the Arduino's digital ports. Th to $12 \mathrm{C}$ port (SCL, SDA) addresses, introducing them to the Arduino raised a problem. pin of these two sensors the Arduino platfornt and untoaded to the characteristics of these sensors, a few tests have been carried on. All the different types of

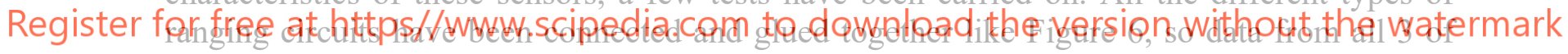
them would be measured almost the same and simultaneously.

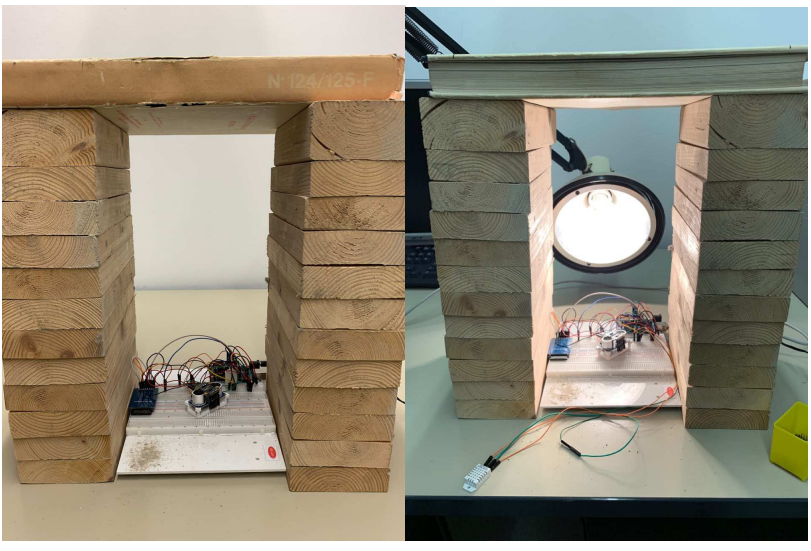

Figure 6. Experiment formation. 


\section{Experiments}

The device was tested against the same measurement against different materials. In Figure 6, 2 tests with and without extreme ambient light have been done for getting the distance from the big book. For the one with the light bulb, the temperature sensor has been moved a bit far from the source of the light and heat. The reason was that the excruciating heat coming from the light bulb would not harm the sensor. The other tested objects were a white paper, a black paper, a clear and transparent plastic cover, and some thin tissues. In Table 6, standard deviations driven from the performed tests have been illustrated.

Table 6. Ranging results of the same experiment under different circumstances.

\begin{tabular}{lrrrrrrr}
\hline Tests & $\begin{array}{c}\text { a } \\
\text { thick } \\
\text { book }\end{array}$ & $\begin{array}{c}\text { a } \\
\text { white } \\
\text { paper }\end{array}$ & $\begin{array}{c}\text { a } \\
\text { black } \\
\text { paper }\end{array}$ & $\begin{array}{c}\text { a transparent } \\
\text { plastic cover }\end{array}$ & $\begin{array}{c}\text { a } \\
\text { tissue }\end{array}$ & $\begin{array}{c}\text { Extreme } \\
\text { ambient } \\
\text { light }\end{array}$ & $\begin{array}{c}\text { Extreme } \\
\text { ambient } \\
\text { light* }\end{array}$ \\
\hline Uitra & 0.61 & 1.87 & 1 & 0.7 & 352 & 3.23 & \\
\hline Laser1 & 2.5 & 2.67 & 7.18 & 5.46 & 4.66 & 3607 & 39.86 \\
\hline Laser2 & 1.5 & 1.48 & 1.87 & 3.12 & 1.62 & 21.94 & \\
\hline
\end{tabular}

On this table, the last column has been created to provide filtered data from the first laser sensor due to the extreme environmental light and heat test. The filter has deleted the ranging out-puts equal to 8190 . When this sensor is not able to read, or the measurement distance is more than its capacity

\section{It should be mentioneit} one to install, had shown

sensor needs $5 \mathrm{v}$ interact only problem with this sensor rate (50Hz data production),
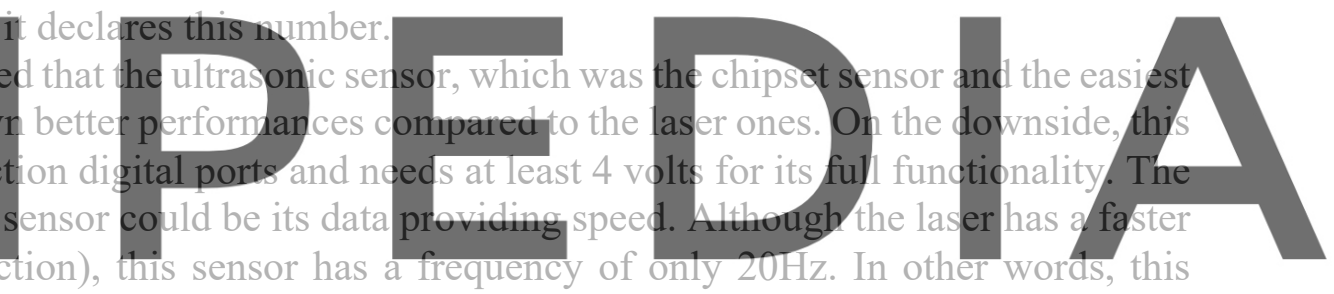
sensor can provide up to 20 data each second. The biggest problem with the ultrasonic sensors

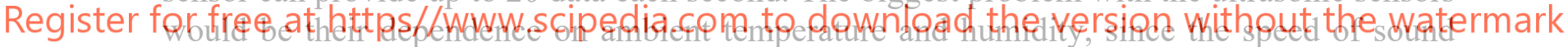

changes from an environment to another. This sensor needs an accurate speed of sound for its calculations. The proposition of this paper would be using the ultrasonic sensor with a laser sensor if there was the probability of changing temperature or of extreme ambient light. Using the first laser sensor or the second one is due to what range and circumstances the experiment may experience.

\section{Conclusion}

Notwithstanding that the laser sensors did not have as good results as the ultrasonic one, they can be useful as well. They are smaller, lighter, and faster than the ultrasonic sensors. Moreover, have noise-free technology (no noise can enter from the wires). Moreover, they work independently of the temperature of their testing situation. Best results will only appear if an ultrasonic sensor (attached to its temperature and humidity sensor) be used alongside a Laser sensor. They can cover the downsides of each other and provide an accurate, useful set of data. The selection of Laser type one or two depends on the circumstances of the experiment. If there is enough budget, Laser type 2 provides a way better set of data and is less sensitive to ambient light. 


\section{Acknowledgments}

The authors are indebted to the Spanish Ministry of Economy and Competitiveness for the funding provided through the research project BIA2017-86811-C2-1-R directed by José Turmo and BIA2017-86811-C2-2-R, directed by Jose Antonio Lozano-Galant. All these projects are funded with FEDER funds. Authors are also indebted to the Secretaria d' Universitats i Recerca de la Generalitat de Catalunya for the funding provided through Agaur (2017 SGR 1482). It is also to be noted that funding for this research has been provided for MR. SEYEDMILAD KOMARIZADEHASL by Agencia Estatal de Investigación del Ministerio de Ciencia Innovación y Universidades grant and the Fondo Social Europeo grant (PRE2018-083238).

\section{ORCID}

Seyedmilad Komarizadehasl: https://orcid.org/0000-0002-9010-2611

Behnam Mobaraki: https://orcid.org/0000-0002-2924-643X

Jose Antonio Lozano Galant: http://orcid.org/0000-0003-0741-0566

Jose Turmo: https://orcid.org/0000-0001-5001-2438

References

Adafruit, (2016). Adafruit VL53L0X Time of Flight Micro-LIDAR Distance Sensor Breakout data-sheet.

Kamal, A. and Hemel, S. (2019). Comparison of Linear Displacement Measurements Between A Mems Accelerometer and Hc-Sr04 Low-Cost Ultrasonic Sensor. ieeexplore.ieee.org.

Komarizadehasl, S., Mobaraki, B., Lozano-Galant, J.A. and Turmo, J. (2020)a. Detailed evaluation of low-cost ranging sensors for structural health monitoring applications, in: International Conference of Recent Trends in Geotechnical and Geo-Environmental Engineering and Education. "RTCEE/RTGEE 2020, 8-12.

Komarizadehasl, S., Mobaraki, B., Lozano-Galant, J.A, and Turme, J. (2020)b. Evaluation of town measuring sensors, in: Engineering and Educatio

Liu, T. (2013). Digital-outpr AM2302) Capacitive-1

Mobaraki, B., Komarizadeh Enviromental Parameters
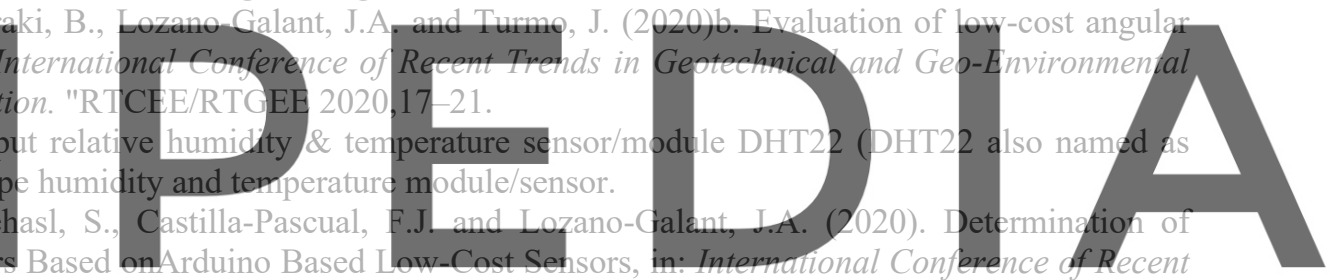
Trends in Geotechnical and Geo-Environmental Engineering and Education. "RTCEE/RTGEE 2020.

Pasha, S. (2016). Thingspeak Based Sensing and Monitoring System for IoT with Matlab Analysis. Int. J. New Technol. Res. 2, 19-23. https://doi.org/ISSN : 2454-4116 